\title{
Desalination processes of sea ice revisited
}

\author{
Dirk Notz ${ }^{1,2}$ and M. Grae Worster ${ }^{1}$ \\ Received 23 April 2008; revised 23 December 2008; accepted 3 February 2009; published 7 May 2009.
}

[1] We reexamine five processes that have been suggested to be important for the loss of salt from sea ice. These processes are the initial fractionation of salt at the ice-ocean interface, brine diffusion, brine expulsion, gravity drainage, and flushing with surface meltwater. We present results from analytical and numerical studies, as well as from laboratory and field experiments, that show that, among these processes, only gravity drainage and flushing contribute to any measurable net loss of salt. We show that during ice growth the salinity field is continuous across the ice-ocean interface. Hence there is no immediate segregation of salt at the advancing front.

Citation: Notz, D., and M. G. Worster (2009), Desalination processes of sea ice revisited, J. Geophys. Res., 114, C05006, doi:10.1029/2008JC004885.

\section{Introduction}

[2] The bulk salinity of sea ice, which is the salinity of a melted sea ice sample, is usually much lower than that of the seawater from which it has formed. Hence the formation and growth of sea ice give rise to a substantial salt flux into the underlying water, increasing both its salinity and density. Properly understanding the strength and intermittency of this salt flux might prove crucial to understanding the World's ocean circulation and its development under future climate conditions when there may possibly be a substantially reduced sea-ice cover but a greater seasonal variation. For example, numerical studies indicate that the formation rate of Antarctic Bottom Water is highly dependent on the amount of salt that is lost from sea ice [Goosse et al., 1997; Stössel et al., 2002]. In the Arctic, the salt loss from sea ice during its formation is thought to contribute to maintaining the Arctic Halocline and gives rise to a variety of local water mass transformations [Aagaard et al., 1981; Skogseth et al., 2005; Stott, 2005].

[3] The salt that remains within sea ice is not incorporated into the solid ice crystals but becomes concentrated in interstitial liquid brine. During all stages of its formation, growth and decay, sea ice remains a mixture of solid freshwater ice and liquid salty brine [e.g., Eicken, 2003, and references therein]. Since many properties of these two phases differ substantially, the bulk properties of sea ice depend strongly on their relative volume or mass fraction, which in turn is a function of the amount of salt remaining in the ice and of local temperature. Hence understanding the processes that lead to the loss of salt from sea ice is not only important in order to understand convection within the underlying ocean, but also for determining the optical, thermodynamic, mechanical, and electrodynamical properties

\footnotetext{
${ }^{1}$ Institute of Theoretical Geophysics, Department of Applied Mathematics and Theoretical Physics, University of Cambridge, Cambridge, UK.

${ }^{2}$ Max-Planck Institute for Meteorology, Hamburg, Germany.

Copyright 2009 by the American Geophysical Union. 0148-0227/09/2008JC004885\$09.00
}

of sea ice itself [Grenfell and Maykut, 1977; Schwerdtfeger, 1963; Ono, 1975; Weeks and Assur, 1967; Morey et al., 1984].

[4] In this paper, we reexamine the relative importance of the processes that have been suggested to contribute to the loss of salt from sea ice. These processes include the initial rejection of salt at the ice-ocean interface expressed by an effective distribution coefficient depending on ice growth velocity [Weeks and Lofgren, 1967; Cox and Weeks, 1975] and the subsequent loss of salt through (1) salt diffusion, (2) so-called brine expulsion, (3) gravity drainage and (4) flushing with surface meltwater, all discussed by Untersteiner [1968]. Here the importance of these processes is quantified using a variety of different experimental and modeling approaches, which we briefly describe in section 2 . In section 3, we describe and discuss each of the possible desalination processes individually, reassessing their relative importance for the loss of salt from sea ice. Finally, we outline possible implications of this work for future modeling and measuring studies.

\section{Experimental and Theoretical Techniques}

[5] We have examined the desalination processes within sea ice using various approaches: an analytical study using conservation equations describing a mushy layer [Feltham et al., 2006]; a numerical evaluation using a one-dimensional enthalpy model [Notz and Worster, 2006]; and experimental studies both in the laboratory and in the field using an instrument capable of high resolution, in situ measurement of the bulk salinity evolution of sea ice [Shirtcliffe et al., 1991; Notz et al., 2005].

\subsection{Analysis}

[6] Neglecting gas inclusions, sea ice can be approximated as a two-phase, two-component porous medium and is therefore an example of a "mushy layer" [Worster, 2000; Feltham et al., 2006]. Note that this term applies to the whole of sea ice and not just a particular layer within it. In this paper we use the terms "sea ice" and "mushy layer" interchangeably. The mushy layer equations governing heat 
and salt conservation in sea ice, in which the salinity of the forming solid phase is zero, are

$$
c_{m} \frac{\partial T}{\partial t}+\rho_{l} c_{l} \mathbf{U} \cdot \nabla T=\nabla \cdot\left(k_{m} \nabla T\right)+\rho_{s} L \frac{\partial \phi_{v}}{\partial t}+Q
$$

and

$$
\left(1-\phi_{v}\right) \frac{\partial S_{b r}}{\partial t}+\mathbf{U} \cdot \nabla S_{b r}=\nabla \cdot\left(D_{S} \nabla S_{b r}\right)+r S_{b r} \frac{\partial \phi_{v}}{\partial t}
$$

[Worster, 1992, 2000]. Here $\phi_{v}$ is the volume fraction of solid ice, $\mathbf{U}=\left(1-\phi_{v}\right) \mathbf{U}_{b r}$ denotes the volume flux of the interstitial brine that moves with velocity $\mathbf{U}_{b r}, r=\rho_{s} / \rho_{l}$ is the density ratio between solid and liquid, and $S_{b r}$ is the salinity of the interstitial brine, which diffuses with an effective diffusivity

$$
D_{S}=\left(1-\phi_{v}\right) D
$$

where $D$ is the diffusivity of salt in water. The heat conductivity and heat capacity of the mushy layer per unit volume, $k_{m}$ and $c_{m}$, are given by volume fraction weighted averages according to

$$
X_{m}=\phi_{v} X_{s}+\left(1-\phi_{v}\right) X_{l}
$$

where $X$ is the respective property and the indices $s$ and $l$ refer to the pure solid and pure liquid phases, respectively.

[7] The second terms on the left-hand sides of equations (1) and (2) describe the transport of heat and salt, respectively, caused by the advection of brine. The second term on the right-hand side of equation (1) governs the release or storage of latent heat caused by internal phase changes, and the last term in equation (1) describes internal heating due to radiation. In equation (1), $L$ is the local difference in specific enthalpy between the liquid and solid phases, and is a function of temperature. To a good approximation, $L=$ $L_{0}\left(1-\phi_{v} \Delta \rho / \rho_{m}\right)$, where $L_{0}$ is the (constant) latent heat at a reference temperature of zero degrees Celsius, $\rho_{m}$ is the phase fraction weighted density, and $\Delta \rho=\rho_{s}-\rho_{l}$ denotes the difference between solid and liquid density [see Notz, 2005 , for details].

[8] In order to find an analytical solution to equations (1)(4), an expression for the volume flux of brine $\mathbf{U}$ is needed. In the absence of gravitational overturning, for example for upward growing ice in a tank cooled from below [see Huppert and Worster, 1985, Table 1], a nonzero velocity field $\mathbf{U}$ is only caused by expansion and contraction during freezing and melting, as discussed below in the context of brine expulsion. Its magnitude can be derived from the mass conservation law

$$
\frac{\partial \rho_{m}}{\partial t}+\nabla \cdot\left(\rho_{l} \mathbf{U}\right)=0 .
$$

Approximating $\rho_{l}$ and $\rho_{s}$ as constant, this can be combined with equation (4) to give

$$
\nabla \cdot \mathbf{U}=(1-r) \frac{\partial \phi_{v}}{\partial t}
$$

The approximation of constant $\rho_{l}$ and $\rho_{s}$ simplifies the solution significantly. It has only a negligible impact on the quantitative values of the solution since (1) $\rho_{s}$ only changes by less than $1 \%$ over the temperature range of interest here and (2) $\rho_{l}$ is always multiplied by the liquid fraction, which becomes very low at low temperatures.

[9] Finally, for an analytical solution an expression describing the relationship between the brine salinity and temperature is required. These are coupled by the liquidus relationship for sea ice. Even though a linear fit is often used for this relationship, given the large temperature range encountered in natural sea ice, a third-order fit

$$
S_{b r}=-21.4 T-0.886 T^{2}-0.0170 T^{3}
$$

is preferable for accurate predictions at lower temperatures. Here $T$ is in ${ }^{\circ} \mathrm{C}$. For the temperature range $-22^{\circ} \mathrm{C}$ to $0^{\circ} \mathrm{C}$, this fit results in a maximum deviation of less than $5 \%$ between the calculated brine salinity and the data presented by Assur [1958], with higher accuracy at lower temperatures. It is difficult to find an accurate fit for the full temperature range, because sodium sulfate starts to precipitate at $-8.2{ }^{\circ} \mathrm{C}$, which changes the slope of the liquidus relationship at this temperature [see Cox and Weeks, 1986; Notz, 2005, for further discussion].

[10] For constant boundary conditions, equations (1)-(6) can be solved to predict the evolution of sea ice without gravitational effects [e.g., Chiareli and Worster, 1992; Worster, 2000; Notz, 2005]. The solution is self-similar, i.e. its shape does not depend on ice thickness. The similarity solution is used in this paper to examine the properties of the ice-ocean interface in section 3.1 and the importance of brine expulsion in section expulsion.

\subsection{Numerical Modeling}

[11] To examine the importance of varying boundary conditions, typical of natural sea ice, a numerical model is convenient. For this work, we have used a one-dimensional sea ice model that allows the study of the evolution of the internal structure and bulk salinity field of sea ice as well as its interaction with radiative processes, melt ponds, oceanic heat and salt fluxes, and surface heat fluxes on a single domain. The model is described in detail by Notz and Worster [2006], which is why we only outline its general design here.

[12] Our model is based on the enthalpy method [Beckermann and Wang, 1995; Oertling and Watts, 2004; Petrich et al., 2006] rather than on front-tracking methods typical of most current sea ice models [e.g., Maykut and Untersteiner, 1971; Semtner, 1976]. In the latter, the evolution of the ice-ocean interface is calculated from the Stefan condition

$$
\rho_{s} L \phi_{v} \frac{\mathrm{d} h}{\mathrm{~d} t}=F_{i}-F_{w},
$$

where $\phi_{v}$ is the solid fraction of the sea ice at the interface, $h$ is ice thickness, $t$ is time, and $F_{i}$ and $F_{w}$ are the heat fluxes in the ice and in the water at the interface. However, as discussed in section 3.1, the solid fraction at the interface of growing sea ice is zero, which implies that the latent heat released at the interface is also zero. There is no "jump" in either heat flux or solid fraction at this interface. The Stefan 


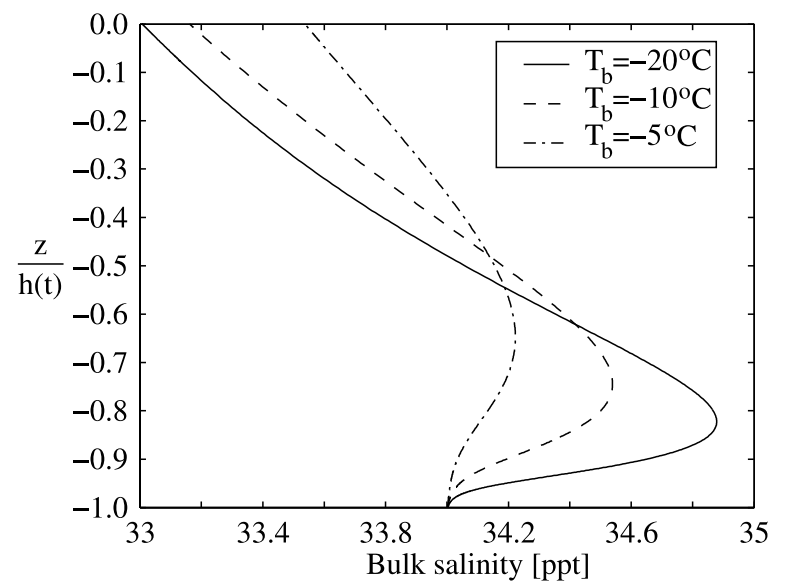

Figure 1. Salinity profiles of sea ice without gravity drainage as obtained from the similarity solution for three different surface temperatures $T_{\mathrm{s}}$. The three curves were calculated for ice formed from seawater with an initial concentration of 34 psu growing into water with an initial temperature of $-1.7^{\circ} \mathrm{C}$. The depth $z$ within the ice is scaled with the ice thickness $h(t)$. Note that the average salinity remains constant at $34 \mathrm{ppt}$.

condition can therefore not be used straightforwardly in a continuum model of sea ice, whereas the enthalpy method simply "captures" the position of the interface.

[13] The numerical model is based on a stationary vertical grid. The main model variables are the enthalpy (heat) and salt content within each of the grid cells. From these two variables, the temperature and the solid fraction within a certain grid cell can unambiguously be determined a posteriori. They are linked to the enthalpy $H$ of a certain grid cell according to

$$
\begin{aligned}
H\left(T, \phi_{m}\right)= & -L \phi_{m}+\phi_{m} \int_{T_{0}}^{T} c_{S}\left(T^{\prime}\right) \mathrm{d} T^{\prime} \\
& +\left(1-\phi_{m}\right) \int_{T_{0}}^{T} c_{l}\left(T^{\prime}, S_{b r}\right) \mathrm{d} T^{\prime},
\end{aligned}
$$

where $T_{0}$ is a reference temperature. The first term on the right-hand side, which is zero for all cells that are fully liquid, describes the latent heat content of the cell, whereas the second and third terms describe the sensible heat content in the solid and in the liquid relative to the reference temperature $T_{0}$. The solid mass fraction is linked to the bulk salinity $S_{b u}$ according to

$$
\phi_{m}\left(T, S_{b u}\right)=1-\frac{S_{b u}}{S_{b r}(T)},
$$

because the bulk salinity of sea ice is defined as

$$
S_{b u}=\phi_{m} \cdot \underbrace{S_{\text {pure ice }}}_{=0}+\left(1-\phi_{m}\right) \cdot S_{b r} .
$$

The solid mass fraction $\phi_{m}$ and the solid volume fraction $\phi_{v}$ are linked through

$$
\left(1-\phi_{m}\right)=\frac{\rho_{l}}{\rho_{m}}\left(1-\phi_{v}\right)
$$

The ice-ocean interface is given as the lower-most grid cell with a nonzero solid fraction. Both the salt and energy content of a certain grid cell can change because of diffusion or advection by moving brine. The energy content can also change because of absorbed radiation.

[14] Unfortunately our current understanding of gravity drainage is too limited for it to be implemented directly into the one-dimensional model at this stage. Apart from this, our model allows the quantification of all other processes that have been suggested to contribute to the desalination of sea ice.

\subsection{Experimental Techniques}

[15] Measurements of the temporal and spatial evolution of the salinity profile in sea ice are needed in order to obtain data sets against which to test analytical and numerical predictions and to examine the impact of gravity drainage that cannot yet fully be examined theoretically. Both in laboratory and field studies, we here used a new instrument capable of measuring the evolution of the bulk salinity and solid fraction profiles in sea ice and other mushy layers in situ with a very high spatial and temporal resolution [Notz et al., 2005]. The instrument consists of a series of thin wire pairs at different depth levels in the ice. By measuring the electrical impedance between the wires of any such pair and the temperature at the same depth, both the solid fraction and the local bulk salinity can be measured in situ with very high temporal resolution. Each wire is 14 centimeters long and any measurement of sea ice properties is averaged along this length of the wires. It was used in a number of field campaigns in the Arctic, where salinity profiles of newly forming sea ice were measured over the course of up to 10 days [Notz and Worster, 2008] and in complementary laboratory experiments [Notz, 2005; Notz et al., 2005]. We describe some of our results here, where they inform our quantitative modeling ideas.

\section{Desalination Processes of Sea Ice}

\subsection{Segregation at the Ice-Ocean Interface}

[16] It is often assumed that most of the salt rejected by sea ice is expelled at the advancing ice-ocean interface. Such rejection is described using an effective distribution

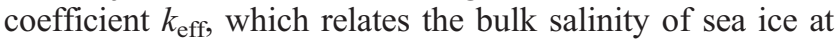
the interface to the salinity of the underlying ocean. Cox and Weeks [1975, 1988] applied the so-called "Burton-PrimSlichter (BPS) model" [Burton et al., 1953] to in situ salinity measurements of growing $\mathrm{NaCl}$ ice in a laboratory. They derived empirical estimates of $k_{\mathrm{eff}}$ as a function of ice growth velocity. However, the BPS model was developed for the study of single-crystal alloys, and more recent understanding of the dynamics of mushy layers suggests that it is not directly applicable to the growth of sea ice, for example.

[17] This becomes clear from Figure 1, which shows the bulk salinity field in growing sea ice for three different constant surface temperatures predicted without any gravitational effects but including the influence of internal density changes. For constant boundary conditions, the salinity profile is self-similar and independent of ice thickness: the salinity is a function of $z / h(t)$, as shown. These particular profiles were obtained by solving the mushy layer 


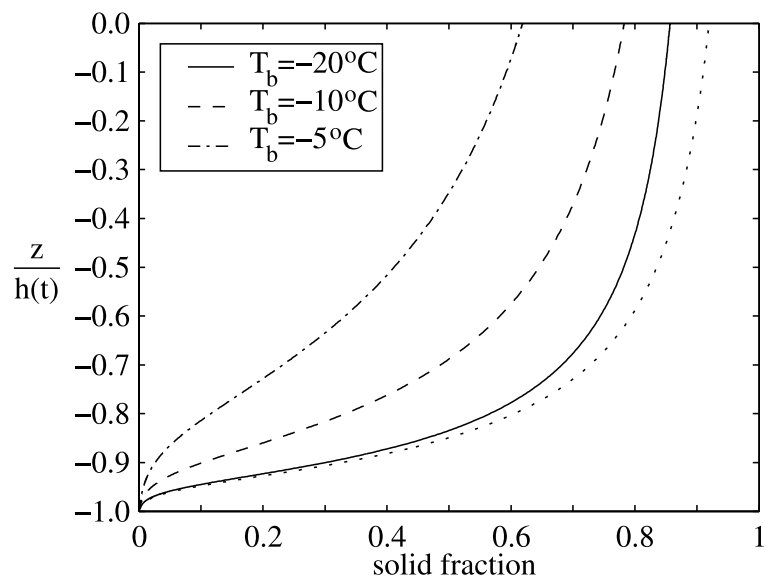

Figure 2. Solid fraction profiles of sea ice without gravity drainage as obtained from the similarity solution for the same setup as in Figure 1. Additionally shown is the solid fraction profile obtained from using the linear liquidus relationship in the similarity solution for $T_{\mathrm{s}}=-20^{\circ} \mathrm{C}$ (dotted line).

equations for 34 psu seawater, initially at a temperature of $-1.7^{\circ} \mathrm{C}$. Independent of surface temperature, all salinity profiles approach the initial salinity of the seawater at the ice-ocean interface. This shows that no salt is rejected at the interface, irrespective of ice growth velocity, which is naturally very different for the three different surface temperatures.

[18] This result can be understood by considering the solid fraction profiles that are plotted in Figure 2, again scaled with ice thickness. Despite the fact that the mushy layer equations allow in principal for a jump in solid fraction at the interface, it can be shown that during growth the solid fraction generally approaches zero at the ice-ocean interface when the Lewis number $L e=\kappa / D$ is very much greater than unity [Worster, 1986; Chiareli and Worster, 1992]. This can qualitatively be understood as follows: In the limit of very low salt diffusivity, the salt field can be approximated as stationary. Hence directly at the advancing front the bulk salinity $S_{b u}$ will be equal to that of the far field ocean water. Since the liquid fraction is given as $S_{b u} / S_{b r}(T)$ and since the brine salinity at the onset of freezing is by definition equal to the ocean-water salinity at the interface, the liquid fraction directly at the front is unity, hence the solid fraction there is zero. For seawater, the salt diffusivity $D \approx 6.8 \cdot 10^{-10} \mathrm{~m}^{2} \mathrm{~s}^{-1}$, whereas the heat diffusivity $\kappa \approx$ $1.2 \cdot 10^{-7} \mathrm{~m}^{2} \mathrm{~s}^{-1}$, which gives $L e \approx 170 \gg 1$. Since the solid fraction profile at the ice-ocean interface is continuous during ice growth, as well as the temperature and the resulting brine salinity, it follows from equation (7) that the bulk salinity field is continuous as well.

[19] As discussed in section 3.4, recent research in mushy layer dynamics has shown that brine fluxes from sea ice are governed by buoyancy, mediated by the permeability of the layer [e.g., Worster, 1992; Wettlaufer et al., 1997]. In other words, any effective segregation that tries to capture the underlying physics should depend on these physical properties and not just on the ice growth rate. The effective distribution coefficient used in the BPS model does not depend on gravity, and the solution shown in Figures 1 and
2 gives an extreme counterexample to the applicability of the model for the simulation of sea ice.

[20] As an aside, Figure 2 also shows the solid fraction field that would result for $T_{\mathrm{s}}=-20^{\circ} \mathrm{C}$ if the brine salinity were calculated according to the linear function $S_{b r}=-18.48 \cdot T$ rather than the higher order fit given in equation (6). Note that the liquid fraction at the top of the layer is then underestimated by roughly $50 \%$, which leads to large errors in the calculation of the permeability of the ice, for example. For this reason it can be important to use the nonlinear relationships given by Cox and Weeks [1986] or equation (6) in the calculation of brine salinity.

[21] The continuity of the bulk salinity field of growing sea ice across the ice-ocean interface also holds for varying boundary conditions and for natural and artificial sea ice under the influence of gravity [Cox and Weeks, 1975; Notz and Worster, 2008; Notz et al., 2005]. Confirmation of this idea is shown in Figure 3, which displays results from a field experiment in which the salinity of young Arctic sea ice was measured in situ using the instrument described by Notz et al. [2005]. The measurements show clearly the continuity of the salinity field across the ice-ocean interface. In contrast, an ice core taken from the same site shows a clear jump in salinity at the interface, which is caused by the loss of brine during sampling. It is worth noting that Cox and Weeks [1975] measured continuous salinity profiles just as we have. Their effective segregation coefficient was measured in terms of the difference between the bulk salinity in the water and that measured $3 \mathrm{~cm}$ above the interface, which they refer to as "above the skeleton layer." It may be that the visually distinct "skeleton layer" is a region of active buoyancy driven convection and that the measurements of Cox and Weeks will prove valuable in better understanding this important desalination process.

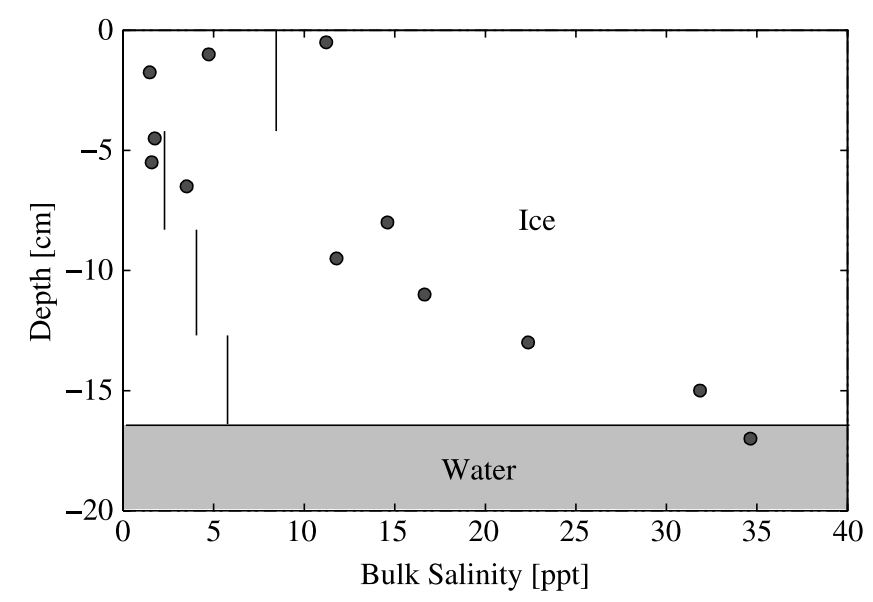

Figure 3. Bulk salinity of young sea ice as measured in a field experiment in situ with the new impedance-based instrument (dots) and using an ice core (lines). Note that these measurements were taken in very thin young ice, which causes the profiles to look very different throughout almost the entire thickness of the ice. Adapted from Notz et al. [2005] (reprinted from the Journal of Glaciology with permission of the International Glaciological Society). 


\subsection{Brine Diffusion}

[22] Historically the first mechanism that was suggested to explain the desalination of sea ice after its initial formation was brine pocket migration, which was proposed by Whitman [1926]. A description of this process as it might apply to sea ice is given by Untersteiner [1968]. It is a diffusive process based on the following idea. During winter, any brine pocket present within the ice has a colder upper and a warmer lower part. To maintain phase equilibrium, this temperature gradient corresponds with a salinity gradient within the brine pocket, with higher salinities toward its top. Molecular salt diffusion caused by this gradient leads to a slow downward motion of salt within the brine pockets. Consequently, the salinity in the top part decreases and some of the water of the brine pocket freezes to maintain phase equilibrium. On the other hand, dissolution occurs at the lower end of the brine pocket caused by the excess salt. Thus any brine pocket moves slowly toward its warmer end and might eventually leave the ice at the iceocean interface. However, both experimental and theoretical studies show that the migration velocities are far too small to allow for any significant salt loss from the ice [Kingery and Goodnow, 1963; Hoekstra et al., 1965; Shreve, 1967]. For example, Untersteiner [1968] estimated a downward migration of a brine pocket close to the surface of the ice during winter of only about $2 \mathrm{~cm}$, which is nearly compensated by a similar upward movement during summer. It is now generally agreed that brine pocket diffusion does not play any significant role in desalinating sea ice under natural conditions.

[23] While earlier quantitative models of brine pocket migration were based on isolated, closed regions of brine (usually spheres), the mechanism simply relies on salt diffusion and phase equilibrium. The net fluxes from this process can be calculated using the mushy layer equations and are independent of the interstitial morphology. The conservation of the mass of salt in a certain volume is given as

$$
\frac{\partial}{\partial t} \rho_{m} S_{b u}=\rho_{l} \nabla \cdot\left(D_{S} \nabla S_{b r}\right)-\nabla \cdot\left(\rho_{l} S_{b r} \mathbf{U}\right),
$$

from which equation (2) can be derived by applying the product rule of differentiation and applying equation (7) with $\phi_{m} \approx \phi_{v}$. Since $\mathbf{U}$ is the pressure driven or buoyancy driven brine flux, which is unrelated to salt diffusion, the equation describing pure salt diffusion can be derived from equation (9) by using equation (7) and equation (8) to give

$$
\frac{\partial}{\partial t} \rho_{m} S_{b u}+\nabla \cdot\left(\rho_{m} S_{b u} \mathbf{v}\right)=0
$$

where

$$
\mathbf{v}=\frac{D}{S_{b r}} \nabla S_{b r}=-D \frac{S_{b r}^{\prime}(T)}{S_{b r}} \nabla T
$$

is the apparent advection velocity for brine caused by diffusion. This is equivalent to the velocity of an isolated brine pocket moving up the temperature gradient [e.g., Hoekstra et al., 1965] and shows that the speed of salt diffusion is independent of the geometrical distribution or interconnectedness of the brine inclusions. It only depends on the temperature distribution in the ice. This apparent advection velocity was shown by Rempel et al. [2001] to cause migration of certain paleoclimate signals in ice cores, and was termed "anomalous diffusion" by those authors, because the brine is transported toward warmer regions $\left(S_{b r}^{\prime}\right.$ is negative and hence $\mathbf{v}$ is in the direction of $\nabla T$ ).

[24] Typical advection velocities estimated from a temperature gradient of $10^{\circ} \mathrm{C} / \mathrm{m}$, a brine diffusivity of $D \approx 6.8$. $10^{-10} \mathrm{~m}^{2} \mathrm{~s}^{-1}$, a brine salinity of about $100 \mathrm{ppt}$ and a slope of the liquidus relationship of about $20 \mathrm{ppt} /{ }^{\circ} \mathrm{C}$ are about $10^{-9} \mathrm{~m} / \mathrm{s}$, or about $4 \mathrm{~cm} / \mathrm{a}$, which shows that the contribution of diffusion to the salt loss from sea ice is negligible both as far as individual brine pockets are concerned as well as with respect to the interconnected brine network.

\subsection{Brine Expulsion}

[25] The density of ice is approximately $10 \%$ lower than that of water. Therefore whenever internal phase changes occur in sea ice caused by changes in the local temperature the volumes of the brine cavities change and cause a pressure gradient which drives brine upward or downward. This mechanism was suggested by Bennington [1963], who considered the growth season of sea ice during which brine is transported downward owing to the continuously decreasing temperature at all levels within the ice. A combination of measurements with analytical equations led Cox and Weeks [1975] to conclude that brine expulsion alone cannot explain the observed changes in ice salinity but that it is the dominant mechanism of desalination during the first stage of sea ice formation.

[26] However, assuming a purely downward motion of the brine and integrating the velocity field that is caused by brine expulsion (equation (5)) over the whole ice thickness $h$ yields

$$
\int_{0}^{h(t)} \nabla \cdot \mathbf{U d} z=\int_{0}^{h(t)}\left(1-\frac{\rho_{s}}{\rho_{l}}\right) \frac{\partial \phi_{v}}{\partial t} \mathrm{~d} z
$$

which results in

$$
\begin{aligned}
U(h(t)) & =\left(1-\frac{\rho_{s}}{\rho_{l}}\right)\left(-\frac{\mathrm{d} h}{\mathrm{~d} t} \phi_{v}(h)+\frac{\mathrm{d}}{\mathrm{d} t} \int_{0}^{h(t)} \phi_{v} \mathrm{~d} z\right) \\
& <\left(1-\frac{\rho_{s}}{\rho_{l}}\right) \dot{h}(t),
\end{aligned}
$$

since $\phi_{v}$ is always less than unity and $\phi_{v}(h)=0$, as was discussed in section 3.1. Because $\left(1-\rho_{s} / \rho_{l}\right)$ is less than unity as well, the brine velocity caused by brine expulsion at the lower interface is always less than the growth rate $\dot{h}$ of the ice at the lower interface, despite the assumption that all brine moves toward that interface. Therefore brine expulsion by expansion alone cannot cause brine to leave the ice at any stage of sea ice formation, but only leads to its redistribution within the sea ice. Even though this derivation strictly applies only for constant boundary conditions, the result holds for realistically varying boundary conditions, as can be shown with our one-dimensional enthalpy model [Notz and Worster, 2006]. 
[27] An example of the salinity profile that is caused if brine expulsion alone were acting in sea ice is shown in Figure 1. Even though there is a clear signal of the downward transported brine, with lower salinities at the top and higher salinities toward the bottom of the ice, the average salinity of all profiles remains constant at the initial seawater value of 34 ppt: there is no transport of salt to the ocean. The finding by Cox and Weeks [1975] that brine expulsion does lead to salt loss from sea ice can possibly be explained by small deviations in their temperature measurements, since the equations used in their model are essentially the same as those that are used in this work. Untersteiner [1968] suggests a rectification of this process between winter and summer (freeze and thaw) owing to air bubbles being rapidly expelled during expansion-induced fracturing of the ice. It may also be the case that, by transporting salt to the lower parts of the mushy layer and increasing the porosity there expansion-driven flow enhances gravity drainage.

\subsection{Gravity Drainage}

[28] As mentioned above, any temperature gradient in sea ice is accompanied by a salinity gradient in the interstitial brine to maintain phase equilibrium. In nature, when an ice floe is cooled from above during winter, the brine density profile is unstable, with the highest densities at the top of the ice. Depending on the permeability of the sea ice, this can result in convective overturning of brine within the mushy ice and the replacement of some of the brine with underlying seawater. This is referred to as gravity drainage.

[29] Having quantified the other processes that have been suggested to contribute to the loss of salt in the absence of surface melting and shown them to be weak or nonexistent, it can be concluded that, during winter, gravity drainage is the dominant mechanism leading to the observed salt loss from sea ice. Salinity profiles measured in first-year sea ice before the onset of the summer melt period can hence usually be fully explained by gravity drainage, with only a minor internal redistribution of salt caused by brine expulsion.

[30] Cox and Weeks [1975] estimated the amount of gravity drainage in growing sea ice from measurements of bulk salinity profiles. They used this data to estimate the rate of change of salinity at a given level. They correlated their findings in an expression that suggests that gravity drainage is just a function of the local temperature gradient and the local solid fraction, and is only active in regions of the mushy layer where the local solid fraction is below 0.95 .

[31] In contrast to these results, which predict a continuous loss of salt as long as the local solid volume fraction is sufficiently low, Wettlaufer et al. [1997] found in laboratory experiments that no salt is lost from sea ice until a critical thickness has been reached. Such a delay in the onset of brine drainage was also found in laboratory studies carried out for the present work. This was explained by Wettlaufer et al. [1997] in terms of a Rayleigh number for the mushy layer

$$
R a=\frac{g \rho_{l} \beta \Delta S_{b r} \Pi\left(\overline{\phi_{v}}\right) h}{\kappa \mu},
$$

which must exceed a critical value before convection can begin [Worster, 1992, 1997, 2000]. In this expression, $g$ is the acceleration due to gravity, $\rho_{l} \beta \Delta S_{b r}=\rho_{l} \beta\left(S_{\text {seawater }}-\right.$ $\left.S_{\mathrm{br}, \text { surf }}\right)$ is the difference in the liquid density across the total ice layer, where $S_{\text {seawater }}$ is the salinity of the underlying saltwater and $S_{\mathrm{br}, \text { surf }}$ is the brine salinity determined by the surface temperature, $h$ is ice thickness, $\kappa$ is thermal diffusivity, $\mu$ is the dynamic viscosity of the liquid and $\Pi\left(\overline{\phi_{v}}\right)$ is the effective permeability of the ice as a function of the mean solid volume fraction across the full ice thickness $\overline{\phi_{v}}$. For thin ice, the available potential energy $g \rho_{l} \beta \Delta S_{b r} h$ can be too small to overcome the dissipative effects of thermal diffusion $\kappa$ and viscosity $\mu / \Pi\left(\overline{\phi_{v}}\right)$. It is this competition that is encapsulated in the Rayleigh number and explains the measured delay in the onset of salt release in their tank experiments. Note that even though the convection is driven by $\Delta S_{b r}$, it is the thermal diffusivity $\kappa$ that is important to estimate the onset and strength of convection [Worster, 2000]. This is due to the fact that it is the diffusive change in temperature which determines the salinity of the convecting brine.

[32] Our experiments, in which we measured profiles of solid fraction, show the further detail that convection often does not occur over the entire thickness of the existing ice, but only in an actively convecting region adjacent to the icewater interface. Hence we employ a local Rayleigh number

$$
R a_{z}=\frac{g \rho_{l} \beta \Delta S_{b r, z} \Pi\left(\phi_{v, \max }\right)(h-z)}{\kappa \mu},
$$

where $\rho_{l} \beta \Delta S_{b r, z}$ is the difference between the density of the underlying water and that of brine at level $z$ and $\Pi\left(\phi_{v, \text { max }}\right)$ is the effective permeability of the ice based on the maximum solid volume fraction $\phi_{v, \max }$ between $z$ and the ice-ocean interface [see also Tait and Jaupart, 1992; Aussillous et al., 2006].

[33] Using a Rayleigh number defined in this way allows us to analyze the gravity drainage that we measured in our laboratory experiments. Figure 4a shows, for example, the measured bulk salinity profile at the end of a laboratory experiment in which a $34 \mathrm{ppt} \mathrm{NaCl}$ solution with an initial temperature of $-1.0^{\circ} \mathrm{C}$ was cooled from the top for 48 hours with a constant temperature of $-10^{\circ} \mathrm{C}$. The increase in salinity between the first and second position from the top is probably not real, but caused by a failure of the thermistor at the second level. The salinity profile shows some resemblance of a double $\mathrm{C}$ shape, with a local maximum in salinity at around $8 \mathrm{~cm}$ depth. The formation of this maximum can be understood by considering the evolution of the maximum Rayleigh number in the ice. Whenever the ice reached a wire pair of our instrument, the Rayleigh number at the position of all wires within the ice was calculated, shown for some of the wires in Figure 4b. For each ice thickness, the maximum of these Rayleigh numbers is plotted in Figure 4c. In the calculation of $R a$ from equation (10), the distance of each wire to the ice-water interface was used for $z$ and the permeability $\Pi$ of the ice at each wire was calculated according to

$$
\Pi=10^{-17}\left[10^{3}\left(1-\phi_{v}\right)\right]^{3.1} \mathrm{~m}^{2},
$$

as measured by Freitag [1999] in young sea ice. The minimum value of $\Pi$ that was found between a certain wire 
(a)

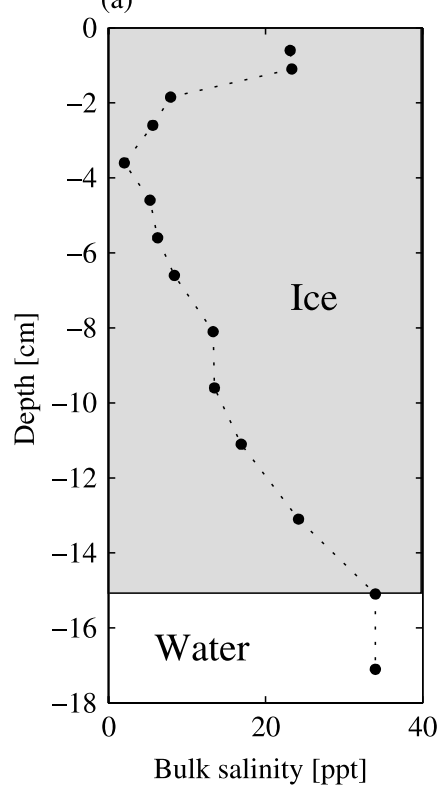

(b)

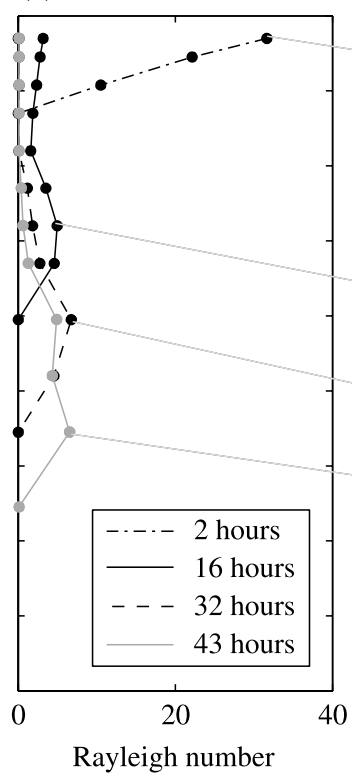

(c)

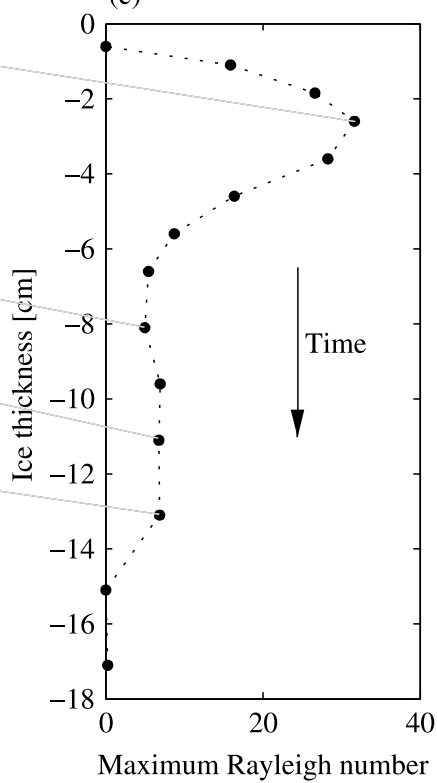

Figure 4. (a) Bulk salinity profile at the end of an experiment in which a $\mathrm{NaCl}$ solution with a concentration of $34 \mathrm{ppt}$ was cooled from above with a constant temperature of $T_{\mathrm{s}}=-10^{\circ} \mathrm{C}$. (b) Rayleigh number profiles at various times during the experiment. The maximum value of each profile is plotted at the respective ice thickness in Figure 4c. (c) Maximum Rayleigh number as a function of ice thickness as it evolves in time. The maximum Rayleigh number was obtained from vertical profiles of the Rayleigh number whenever the ice-water interface reached a wire pair of the impedance instrument.

and the ice-water interface was used in the calculation of the Rayleigh number.

[34] Figure 4c shows that $R a_{\max }$ increases initially, until it reaches a critical value and convection starts. The mush that was formed before this time loses less brine than that formed after the onset of convection, which explains the relatively high bulk salinities toward the ice surface. According to equation (7), the decrease in bulk salinity leads to a decrease in liquid fraction $\left(1-\phi_{v}\right)$, which in turn causes a decrease in permeability $\Pi$. The Rayleigh number therefore decreases as well, despite the increasing ice thickness. It finally remains around a value of 7 , similar to what was found in field experiments [Notz and Worster, 2008] and laboratory experiments [Tait and Jaupart, 1992], and within the range of critical Rayleigh numbers found theoretically [Worster, 1992].

[35] Even though further experimental and theoretical studies are required to enhance our understanding of gravity drainage, an understanding of the Rayleigh number captures most of the observed features such as the initial delay in the onset of gravity drainage in certain laboratory experiments and the possible formation of multiple $\mathrm{C}$ profiles for constant boundary conditions. Such multiple C profiles can form as follows: After the onset of convection, bulk salinity and hence liquid fraction decreases in the convecting region. This lowers permeability and hence the Rayleigh number, which can become subcritical. Once this happens convection stops, leading to higher bulk salinities in the sea ice that forms underneath the previously convecting region. Only if enough of the new high salinity sea ice has formed, the Rayleigh number can become supercritical again and convection can start anew. In applying this approach to sea ice, only the thickness of the actively convecting region should be used for the calculation of $R a$, as outlined above.

[36] In natural settings, sea ice forms in consequence of heat transfers to the atmosphere. The surface temperature of the ice decreases gradually from the ocean temperature as the ice thickens initially and the solid fraction is consequently smaller than in the step-freezing laboratory experiments. The Rayleigh number is correspondingly larger for a given ice thickness and a delay in the onset of brine drainage is not guaranteed. However, Wettlaufer et al. [2000] found such a delay in oceanographic measurements below growing ice in a lead and showed it to be consistent with measurements of temperature and inferred solid fractions in the sea ice, with reference to the Rayleigh numberbased criterion they had determined in the laboratory. However, the balance is quite fine in these circumstances and we did not find a significant delay in brine drainage in our field experiments. Further investigation of the delay of brine drainage are warranted and it would be particularly useful to undertake tank studies with a free surface, which allow the slow evolution of surface temperature, to complement the tank studies with fixed surface temperatures.

\subsection{Flushing}

[37] The fifth mechanism that has been suggested to contribute to the loss of salt from sea ice is "flushing," which refers to the "washing-out" of salty brine with relatively fresh surface meltwater during summer. The pressure overhead of the meltwater is the driving force of the downward movement of brine, the scale of which can be calculated from Darcy's law [e.g., Eicken et al., 2004]. In order to examine the impact of the percolating meltwater on the salinity field of the underlying sea ice, we have used the 
(a)

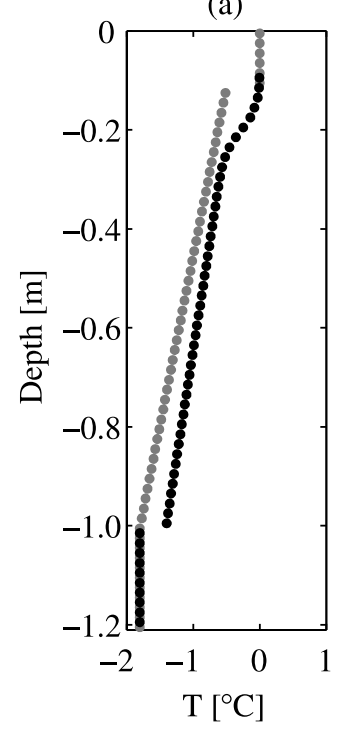

(b)

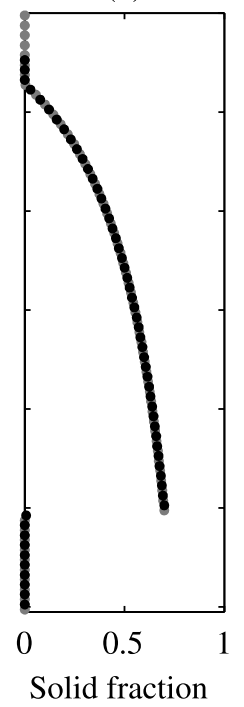

(c)

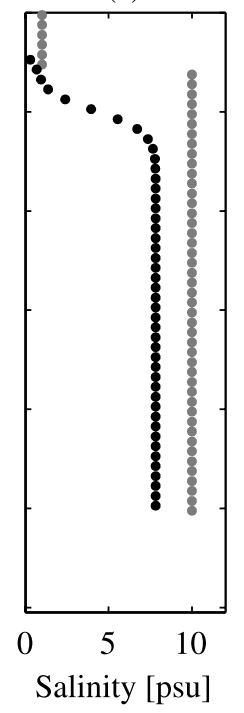

\section{- Initital state}

- Final state

Figure 5. Vertical profiles of (a) temperature, (b) solid fraction, and (c) bulk salinity before and after a 1-hour model run with flushing.

one-dimensional model described by Notz and Worster [2006] to simulate summer time flushing of meltwater. It should be noted that a one-dimensional study is not capable of capturing all aspects of flushing, since Eicken et al. [2002, 2004] showed from field experiments that flushing has a significant horizontal component. Nevertheless, since most of the net salt loss caused by flushing is due to the vertical component of the meltwater percolation, our onedimensional model allows one at least to examine the main features of the interaction of surface meltwater with the salinity field of the underlying sea ice.

[38] Flushing is incorporated into the model by calculating the downward displacement of the surface of any meltwater forming on top of the ice from Darcy's law, where the minimum permeability of the underlying sea ice as calculated from equation (11) is taken to be the controlling permeability for the efficiency of the flushing. The salinity change within each grid cell is calculated by applying the continuity equation.

[39] For the purpose of examining the general efficiency of flushing, we carried out a highly simplified modeling experiment. Figure 5 shows results from this study in which sea ice was overlain by a melt pond, the evolution of which was simulated during the course of 1 hour. The sea ice had an initial thickness of $0.9 \mathrm{~m}$, a bulk salinity of $10 \mathrm{ppt}$, and a temperature that increased linearly from $-1.8^{\circ} \mathrm{C}$ at the ice-ocean interface to $-0.5^{\circ} \mathrm{C}$ at the ice melt-pond interface. The melt pond consisted of water with a salinity of $0.5 \mathrm{psu}$ and a temperature of $0^{\circ} \mathrm{C}$. The ocean water underneath the ice had a temperature of $-1.8^{\circ} \mathrm{C}$ and a salinity of 34 psu.

[40] Figure 5 shows the initial and final temperature, solid fraction, and bulk salinity distribution at the end of the 1-hour-long simulation period. Because of the comparatively high temperature of the ice, the liquid fractions are very high throughout the ice and the flushing is very efficient. After only 1 hour, the melt pond has drained almost completely, and the bulk salinity of the ice has decreased by more than $2 \mathrm{ppt}$ over the whole ice thickness (Figure 5c). As becomes apparent from Figure 5a, the downward percolation of the meltwater has also led to an increase of the temperature throughout the ice, underlining the importance of the brine velocity $U$ in determining the temperature evolution of sea ice in certain cases. This is not represented in most current sea ice models.

[41] Our model results also indicate that after the onset of flushing of surface meltwater, the formation of impermeable layers within the ice that would slow down or even stop the flushing is unlikely. This is exemplified by the fact that the solid fraction of the sea ice remains almost constant in our model run, despite significant changes in $T$ and $S_{b u}$ (Figure $5 b$ ). This can be understood by considering the energy that is needed in order to change the solid fraction significantly. For example, the formation of an impermeable layer in sea ice with an initial solid fraction of $90 \%$ would require a latent heat exchange of $3 \cdot 10^{4} \mathrm{~J} / \mathrm{kg}$, which would be sufficient energy to raise the temperature of the existing solid ice by roughly $15^{\circ} \mathrm{C}$. Given that the solid fraction toward the (melting) surface of the ice would always be much lower than $90 \%$, because the temperature of the melt pond is higher than the bulk melting point of the ice, it seems as if almost impermeable layers are unlikely to form. However, especially early in the melt season, the interplay between the daily cycles of radiative fluxes, the temperature profile in the ice, the low salinity of the surface meltwater is far more complicated than outlined in the qualitative study described here [see Vancoppenolle et al., 2007].

[42] The high efficiency of flushing that was exemplified by the model results described here gives rise to the question as to how melt ponds can be sustained on sea ice for any longer period at all. Employing Darcy's law, the surface of a melt pond evolves according to

$$
z(t)=z\left(t_{0}\right) e^{g \rho_{l} \Pi\left(\phi_{v, \text { max }}\right) /(\mu h)} .
$$

For a viscosity of $\mu=1.79 \cdot 10^{-3} \mathrm{~kg} \mathrm{~m}^{-1} \mathrm{~s}^{-1}$, this gives for $1 \mathrm{~m}$ thick ice an e-folding time of between 3 and 300 minutes for the range of permeabilities between $10^{-9}$ and $10^{-11} \mathrm{~m}^{2}$ that was measured by Eicken et al. [2002]. Hence without the formation of layers in the sea ice that have a very low permeability, any melt pond would drain rapidly and could not be sustained on the ice surface for several days let alone weeks if its surface were above sea level. Measurements by Eicken et al. [2002], as well as recent simulations by Luthje et al. [2005] and Taylor and Feltham [2004], for example, show that through a delicate balance of inflow by surface meltwater and drainage through the underlying sea ice, the surface of melt ponds in the Arctic is indeed usually at sea level, and that melt ponds are only maintained above sea level at the very beginning of the summer melt period, when the ice is sufficiently cold to maintain relatively low permeabilities, especially close to its surface where refreezing snow meltwater can form an impermeable freshwater-ice layer. During the peak of the summer melt season, almost all salt loss from flushing 
occurs because of near-instantaneous trickling through the ice of any meltwater that would otherwise cause the surface of melt ponds on top of the ice to reach above sea level.

\section{Discussion and Conclusions}

[43] In this paper, we have reexamined the processes that have been suggested to contribute to the loss of salt from sea ice. We have shown that no salt is lost from sea ice by segregation at the ice-ocean interface, and that brine expulsion and salt diffusion do not contribute to any measurable salt loss from sea ice, either. All salt loss from sea ice is due to gravity drainage in winter and flushing during summer.

[44] In the light of these results, a different interpretation of the measurements by Cox and Weeks [1975, 1988] seems warranted. They explain most of the salt loss observed in their laboratory experiment by fractionation at the ice-ocean interface and quantify this in terms of a rate-dependent segregation coefficient, with higher salinities obtained at higher growth velocities. However, our results lend further support to the idea that brine drainage is governed by the ice thickness, the permeability, and the brine density gradient [Wettlaufer et al., 1997, 2000]. The high bulk salinity that Cox and Weeks [1975] measured in the ice that had formed at high growth rates can be explained by the fact that, because of the constant surface cooling, these high growth rates occurred at the early stages of the experiment, when the ice was still very thin. Hence similar to the findings by Wettlaufer et al. [1997], the driving potential energy only allowed very limited convection to occur, and relatively large amounts of brine remained within the ice.

[45] Our local measurements of Rayleigh number suggest that the most active convection occurs in a region adjacent to the ice-ocean interface, which is just a few centimeters thick during the early stages of ice growth monitored in the laboratory. This might accord with Cox and Weeks' observation of a "skeleton layer" and the fact that they measured segregation across this layer rather than at the ice-ocean interface itself.

[46] The success of previous studies to reproduce measured salinity profiles using the model of Cox and Weeks [1988] [e.g., Eicken, 1992; Vancoppenolle et al., 2007] may in part be due to the number of free parameters in this model, which includes semiempirical expressions for (1) the loss of salt directly at the ice ocean interface, (2) the loss of salt from brine expulsion and (3) the loss of salt through gravity drainage. For example, after employing the expressions by Cox and Weeks [1988] for fractionation at the iceocean interface and for brine expulsion, Vancoppenolle et al. [2007] reduced the efficiency of gravity drainage by $65 \%$ as compared to the original model in order to reproduce winter salinity profiles that were measured off the Alaskan coast.

[47] In the context of the current work it seems that a more general treatment of the loss of salt from sea ice during winter can be obtained by solely modeling the impact of gravity drainage as a function of a mush Rayleigh number, as expressed by equation (10). The lack of a physically based quantitative description of gravity drainage is currently one of the most significant shortcomings of numerical sea ice models. Unfortunately, currently our theoretical understanding of this processes is too limited to allow for such parameterization to be developed on physical grounds. During the last years, significant understanding of the controls of this process has been obtained from combinations of theoretical, experimental and field studies [Wettlaufer et al., 1997; Notz and Worster, 2008]. Extending these studies will be subject to future work, both theoretical and experimental.

[48] As far as flushing is concerned, its incorporation into a salinity prediction model is probably more straightforward than that of gravity drainage, mostly because for a relatively realistic modeling of flushing, only the driving meltwater head and the permeability of the underlying sea ice must be known. A combination of Darcy's law with the continuity equation allows the prediction of the loss of salt from the underlying ice caused by the slow trickling of surface meltwater into the sea ice, as described by Eicken et al. [2004] and Notz and Worster [2006], for example. A similar, semiempirical approach was recently used by Vancoppenolle et al. [2007] to simulate the summer time evolution of sea ice salinity. Their model was able to represent the slow desalination of the top layers of sea ice and gave, for a certain choice of tuning parameters, results in very good agreement with measurements. A somewhat less empirical approach can, for example, be based on the permeability measurements by Freitag [1999], which allow the calculation of sea ice permeability from a given brine volume fraction. Combining such an approach with a Rayleigh number-based parameterization of gravity drainage will hopefully result in a relatively simple, physically based model of desalination processes in sea ice that can be used both in high-resolution stand-alone models and in somewhat less highly resolved climate models.

[49] Acknowledgments. We thank John Wettlaufer and Marco Restelli for their very extensive and helpful comments on a previous version of this paper. We also thank Martin Vancoppenolle and an anonymous reviewer for their comments, which helped to substantially improve this paper. This work was made possible by support from National Environmental Research Council under grant NER/B/S/2002/00521 (D. Notz and M.G. Worster) and Studienstiftung des Deutschen Volkes (D. Notz), which are both very gratefully acknowledged.

\section{References}

Aagaard, K., L. K. Coachman, and E. C. Carmack (1981), On the halocline of the Arctic Ocean, Deep Sea Res., 28A(6), 529-545.

Assur, A. (1958), Composition of sea ice and its tensile strength, in Arctic Sea Ice; Conference Held at Easton, Maryland, February 24-27, 1958, pp. 106-138, Publs. Natl. Res. Counc. Wash., Washington, D. C.

Aussillous, P., A. J. Sederman, L. F. Gladden, H. E. Huppert, and M. G. Worster (2006), Magnetic resonance imaging of structure and convection in solidifying mushy layers, J. Fluid Mech., 552, 99-125.

Beckermann, C., and C. Y. Wang (1995), Multiphase/scale modeling of alloy solidification, Annu. Rev. Heat Trans., 6, 115-198.

Bennington, K. O. (1963), Some crystal growth features of sea ice, J. Glaciol., 4(36), 669-688.

Burton, J. A., C. Prim, and W. P. Slichter (1953), The distribution of solute in crystals grown from the melt: part I. Theoretical, J. Chem. Phys., 21(11), 1987-1991

Chiareli, A. O. P., and M. G. Worster (1992), On measurements and prediction of the solid fraction within mushy layers, J. Crystal Growth, 125, 487-494.

Cox, G. F. N., and W. F. Weeks (1975), Brine drainage and initial salt entrapment in sodium chloride ice, CRREL Res. Rep. 345, U.S. Army Cold Reg. Res. and Eng. Lab., Hanover, N. H.

Cox, G. F. N., and W. F. Weeks (1986), Changes in the salinity and porosity of sea-ice samples during shipping and storage, J. Glaciol., 32(112), $371-375$. 
Cox, G. F. N., and W. F. Weeks (1988), Numerical simulation of the profile properties of undeformed first-year sea ice during the growth season, J. Geophys. Res., 93(C10), 12,449-12,460.

Eicken, H. (1992), Salinity profiles of Antarctic sea ice: Field data and model results, J. Geophys. Res., 97(C10), 15,545-15,557.

Eicken, H. (2003), From the microscopic to the macroscopic to the regional scale: Growth, microstructure and properties of sea ice, in Sea Ice - An Introduction to Its Physics, Chemistry, Biology and Geology, edited by D. Thomas and G. S. Dieckmanni, pp. 22-81, Blackwell, Malden, Mass

Eicken, H., H. R. Krouse, D. Kadko, and D. K. Perovich (2002), Tracer studies of pathways and rates of meltwater transport through Arctic summer sea ice, J. Geophys. Res., 107(C10), 8046, doi:10.1029/ 2000JC000583.

Eicken, H., T. C. Grenfell, D. K. Perovich, J. A. Richter-Menge, and K. Frey (2004), Hydraulic controls of summer Arctic pack ice albedo, J. Geophys. Res., 109, C08007, doi:10.1029/2003JC001989.

Feltham, D. L., N. Untersteiner, J. S. Wettlaufer, and M. G. Worster (2006), Seaice is a mushy layer, Geophys. Res. Lett., 33, L14501, doi:10.1029/ 2006GL026290.

Freitag, J. (1999), Untersuchungen zur Hydrologie des arktischen Meereises Konsequenzen für den kleinskaligen Stofftransport (in German), Berichte zur Polarforschung 325, Alfred-Wegener Institut für Polar- und Meeresforschung, Bremerhaven, Germany.

Goosse, H., J. M. Campin, T. Fichefet, and E. Deleersnijder (1997), Impact of sea-ice formation on the properties of Antarctic Bottom Water, Ann. Glaciol., 25, 276-281.

Grenfell, T. C., and G. A. Maykut (1977), The optical properties of ice and snow in the Arctic basin, J. Glaciol., 18(80), 445-463.

Hoekstra, P., T. E. Osterkamp, and W. F. Weeks (1965), The migration of liquid inclusions in single ice crystals, J. Geophys. Res., 70(20), 4922 4931.

Huppert, H. E., and M. G. Worster (1985), Dynamic solidification of a binary melt, Nature, 314(6013), 703-707.

Kingery, W. D., and W. H. Goodnow (1963), Brine migration in salt ice, in Ice and Snow: Properties, Processes and Applications, edited by W. D. Kingery, pp. 237-247, MIT Press, Cambridge, Mass.

Luthje, M., D. L. Feltham, P. D. Taylor, and M. G. Worster (2005), Modeling the summer-time evolution of sea-ice melt ponds, J. Geophys. Res., 111, C02001, doi:10.1029/2004JC002818.

Maykut, G. A., and N. Untersteiner (1971), Some results from a timedependent thermodynamic model of sea ice, J. Geophys. Res., 76(6), $1550-1575$

Morey, R. M., A. Kovacs, and G. F. N. Cox (1984), Electromagnetic properties of sea ice, CRREL Rep. 84-2, U.S. Army Cold Reg. and Eng. Lab, Hanover, N. H.

Notz, D. (2005), Thermodynamic and Fluid-Dynamical Processes in Sea Ice, Ph.D. thesis, Univ. of Cambridge, Cambridge, U. K.

Notz, D., and M. G. Worster (2006), A 1-D enthalpy model of sea ice, Ann. Glaciol., 44, 123-128.

Notz, D., and M. G. Worster (2008), In situ measurements of the evolution of young sea ice, J. Geophys. Res., 113, C03001, doi:10.1029/ 2007JC004333.

Notz, D., J. S. Wettlaufer, and M. G. Worster (2005), A non-destructive method for measuring the salinity and solid fraction of growing sea ice in situ, J. Glaciol., 5l(172), 159-166.

Oertling, A. B., and R. G. Watts (2004), Growth of and brine drainage from $\mathrm{NaClH} 2 \mathrm{O}$ freezing: A simulation of young sea ice, J. Geophys. Res., 109 C04013, doi:10.1029/2001JC001109.

Ono, N. (1975), Thermal properties of sea ice IV, CRREL Draft Transl. 467, 19 pp., U.S. Army Cold Reg. Res. and Eng. Lab., Hanover, N. H.

Petrich, C., P. Langhorne, and Z. F. Sun (2006), Modelling the interrelationships between permeability, effective porosity and total porosity in sea ice, Cold Reg. Sci. Technol., 44, 131-144.
Rempel, A. W., E. D. Washington, J. S. Wettlaufer, and M. G. Worster (2001), Possible displacement of the climate signal in ancient ice by premelting and anomalous diffusion, Nature, 411, 568-571.

Schwerdtfeger, P. (1963), The thermal properties of sea ice, J. Glaciol., 4 $789-807$.

Semtner, A. (1976), A Model for the Thermodynamic Growth of Sea Ice in Numerical Investigations of Climate, J. Phys. Oceanogr, 6(3), 379-389.

Shirtcliffe, T. G. L., H. E. Huppert, and M. G. Worster (1991), Measurements of the solid fraction in the crystallisation of a binary melt, J. Crystal Growth, 113, 566-574.

Shreve, R. L. (1967), Migration of air bubbles, vapor figures, and brine pockets in ice under a temperature gradient, J. Geophys. Res., 72(16), 4093-4100

Skogseth, R., P. M. Haugan, and M. Jakobsson (2005), Watermass transformation in storfjorden, Cont. Shelf Res., 25(5-6), 667-695.

Stössel, A., K. Yang, and S.-J. Kim (2002), On the role of sea-ice and convection in a global ocean model, J. Phys. Oceanogr., 32, 1194-1208.

Stott, M. J. (2005), The Arctic Ocean's interaction with wind-driven coastal polynyas and the Barents Sea polar front, Ph.D. thesis, Univ. of Keele, Staffordshire, U. K

Tait, S., and C. Jaupart (1992), Compositional convection in a reactive crystalline mush and melt differentiation, J. Geophys. Res., 97(B5), 6735-6756.

Taylor, P. D., and D. L. Feltham (2004), A model of melt pond evolution on sea ice, J. Geophys. Res., 109, C12007, doi:10.1029/2004JC002361.

Untersteiner, N. (1968), Natural desalination and equilibrium salinity profile of perennial sea ice, J. Geophys. Res., 73(4), 1251-1257.

Vancoppenolle, M., C. M. Bitz, and T. Fichefet (2007), Summer fast ice desalination at Point Barrow, Alaska: Modeling and observations, J. Geophys. Res., 112, C04022, doi:10.1029/2006JC003493.

Weeks, W. F., and A. Assur (1967), The mechanical properties of sea ice, CRREL Monogr. II-C3, U.S. Army Cold Reg. and Eng. Lab., Hanover, N. H.

Weeks, W. F., and G. Lofgren (1967), The effective solute distribution coefficient during the freezing of $\mathrm{NaCl}$ solutions, in Physics of Snow and Ice, vol. 1, edited by H. Oura, pp. 599-610, Inst. of Low Temp. Sci., Hokkaido, Japan.

Wettlaufer, J. S., M. G. Worster, and H. E. Huppert (1997), Natural convection during solidification of an alloy from above with application to the evolution of sea ice, J. Fluid Mech., 344, 291-316.

Wettlaufer, J. S., M. G. Worster, and H. E. Huppert (2000), Solidification of leads: Theory, experiment, and field observations, J. Geophys. Res., 105(C1), $1123-1134$.

Whitman, W. G. (1926), Elimination of salt from seawater ice, Am. J. Sci. Ser., 211, 126-132.

Worster, M. G. (1986), Solidification of an alloy from a cooled boundary, J. Fluid Mech., 167, 481-501.

Worster, M. G. (1992), The dynamics of mushy layers, in Interactive Dynamics of Convection and Solidification, edited by S. H. Davis et al., pp. 113-138, Kluwer Academic, Dortrecht, Netherlands.

Worster, M. G. (1997), Convection in mushy layers, Annu. Rev. Fluid Mech., 29, 91-122.

Worster, M. G. (2000), Solidification of fluids, in Perspectives in Fluid Dynamics, edited by G. K. Batchelor et al., pp. 393-446, Cambridge Univ. Press, New York.

D. Notz, Max-Planck Institute for Meteorology, Bundesstr. 53, D-20146 Hamburg, Germany. (dirk.notz@seaice.info)

M. G. Worster, Institute of Theoretical Geophysics, Department of Applied Mathematics and Theoretical Physics, University of Cambridge, CMS Wilberforce Road, Cambridge CB3 0WA, UK. 